Review

Article

\title{
Recent advances in identification of potential drug targets and development of novel drugs in parasitic diseases. Part I: Drug resistance
}

\author{
Sherif M Abaza
}

Medical Parasitology Department, Faculty of Medicine, Suez Canal University, Ismailia, Egypt

\begin{abstract}
Important obstacles facing programs involved in eradication of tropical diseases are drug resistance and environmental aspects surrounding the infected population including poverty, inefficient healthy sewage system, and popular habits. Treatment failure is determined by either persistence of clinical manifestations after scheduled drug regimen, or occurrence of disease relapse or new infections. This means that treatment failure in clinical studies does not mean drug resistance because identified parasite' resistance to a certain drug does not include pharmacokinetics and pharmacogenetics studies as well as host immunological assessment. Coinfections, drug-drug interactions, and environmental factors also contribute in development of drug resistance. Of note, parasite gene mutation is the main mechanism suggested for drug resistance. The present work aims to review commonly reported drugs associated with resistance, and the proposed genetic markers of resistance.
\end{abstract}

Keywords: drug resistance; gene mutation; genome plasticity, mechanism of resistance; mode of action; pharmacogenetics, pharmacokinetics.

Received: 29 October, 2021, Accepted: 6 December, 2021.

Corresponding Author: Sherif M Abaza, Tel.: +20 1005243428, E-mail: smabaza@hotmail.com.

Print ISSN: 1687-7942, Online ISSN: 2090-2646, Vol. 14, No. 3, December, 2021.

Abbreviations: ABC: ATP-binding cassette; AQP: Aquaglyceroporin; ART: Artemisinin; ATP: Adenosine triphosphate; Cytbc: Cytochrome b complex; CRT: Chloroquine resistance transporter; DHFR: Dihydrofolate reductase; DHPS: Dihydropteroate synthase; GWAS: Genome-wide associated study; MDA: Mass drug administration; MDR: Multidrug resistance; Ras: Rat sarcoma virus protein; ROS: Reactive oxygen species; SNP: Single nucleotide polymorphism.

\section{INTRODUCTION}

A review ${ }^{[1]}$ was published to clarify the importance of long-term strategies' required for eradication of malaria, leishmaniasis, and trypanosomiasis. Scientific researches should focus on protecting the efficacy of the current therapeutic WHOrecommended regimens against the emergence and spread of parasites resistant to the current drugs. Long-term strategies include scientific perception data regarding mechanisms of action and resistance of clinical isolates and continuous identification of potential novel drug targets accompanied with financial support for the targeted compounds in more advanced stages of clinical trials. This assures designing alternative drugs to overcome the emerging resistant strains, and increase the chemotherapeutic arsenal against neglected tropical disease ${ }^{[1]}$.

Drug resistance is defined as the ability of a parasite strain to survive and multiply despite administration of a drug in doses equal to those usually recommended. Generally, a patient's cure is evaluated by clinical examination associated with routine parasitological diagnosis. On the other hand, complete cure or significant treatment outcome should be evaluated using a series of more sophisticated diagnostic methods. Certainly, some endemic tropical diseases require more assays that may be aggressive (e.g., rectal snip in intestinal schistosomiasis, bone marrow biopsy, and splenic aspirate in leishmaniasis), and costly (e.g., PCR techniques). Therefore, drug resistance is not concerned with success or failure of therapy because it is simply a multi-factorial phenomenon related to environmental, drug, host, and parasite factors. Besides, methods utilized to investigate parasites sensitivity or resistance are not inter-laboratory standardized, or tested in in vitro assays, or clinically[2].

Discussing mechanism(s) of drug resistance, scientists should differentiate between two conditions: in vivo drug sensitivity and in vitro parasite susceptibility. In a report, the reviewers ${ }^{[3]}$ claimed that definite scheduled dose and assessment of drug pharmacokinetics and pharmacogenetics in relation to host immune system are conducted in the in vivo studies. Unfortunately, these results are difficult to interpret due to loss of data regarding drug pharmacokinetics and pharmacogenetics. Although in vitro parasite susceptibility studies are expensive and consume much time and labor, results pointed to validated resistance markers if associated with bioinformatics (i.e. transcriptomic, metabolomic and genomic studies). Accordingly, the reviewers concluded that drug resistance is not attributed 
only to emergence of resistant strains after mass drug administration (MDA) ${ }^{[3]}$.

To identify gene mutations responsible for drug resistance in a locality, two steps are recommended: 1) mapping a genetic data base for the known gene mutations; and 2) identification of the putative drugresistance loci in each gene ${ }^{[4]}$. Detailed description of loci, i.e. codons, of gene mutations associated with drug resistance was previously reviewed ${ }^{[5]}$. Detection of drug-resistant strains and their spread was greatly achieved by the discovery of molecular resistance markers. Genome-wide associated studies (GWASs) presented a powerful tool to identify chromosomal regions and their associated genes under high selective drug pressure. To establish a molecular resistance marker for a certain drug, interested laboratories should maintain in vitro reproduction of proliferating resistant strains. This was a hard task for Plasmodium artemisinin (ART) derivatives-resistant strains because it requires almost five years to establish their resistance in vitro. However, Ariey et al. ${ }^{[6]}$ was the first to confirm the genetic marker of ART resistance in Cambodian $P$. falciparum strains.

\section{[I] Anti-malarial drugs}

Environmental factors determining levels of malaria transmission, low, high or seasonal can affect development of drug resistance. While individuals in lower transmission areas possess lower acquired immunity that increases transmission of resistant strains, those in high transmission settings harbor multiple genotypes and resistant strains have to compete with wild-type strains to survive. In seasonal malaria transmission, asymptomatic parasitemia can serve as a reservoir for sensitive strains ${ }^{[7]}$.

Resistance to anti-malarial drugs is attributed to inability of the resistant strains to uptake the drug due to mutations in the parasite genes encoding transporters or enzymes responsible for drug uptake and metabolism, respectively ${ }^{[8]}$. Due to strong selection force of anti-malarial drugs, point mutations have spread through Plasmodium populations over the last three decades ${ }^{[9]}$. Continuous dynamics of drug pressure on the selected linked genes increased the spread of mutant Plasmodium resistant isolates to new geographic areas. Therefore, frequent populationbased studies were strongly recommended to evaluate the efficacy of anti-malarial drugs in a locality ${ }^{[10]}$. In studies concerning anti-malarial drug resistance, three complementary approaches are utilized nowadays. In vivo assessment of drug efficacy in clinical samples, followed by in vitro assays against Plasmodium life cycle stages', and lastly molecular investigations to detect validated gene mutations associated with resistant strains. An important issue was raised for the national and regional authorities to establish a protocol for local anti-malarial drug resistance aiming at maintance and improvement of the surveillance networks worldwide $\mathrm{e}^{[1]}$.

It is worth noting that $P$. falciparum possesses unique complex genomic plasticity that encode multiple transporters. To survive, it is able to 1) delete certain portions of genes unessential for its growth; 2) evade host immune response by antigenic variations; and 3) undergo gene mutations in enzymes controlling drug uptake $^{[11]}$. Cowell and Winzeler ${ }^{[12]}$ discussed another factor, which in conjunction with genome plasticity, contributed in anti-malarial drug resistance. It was observed that high burden of asexual erythrocytic stages increased Plasmodium ability to develop drug resistance. American investigators ${ }^{[13]}$ conducted wholegenome microarray analysis and next-generation deep resequencing on several $P$. falciparum clones. The study propagated six cultures of $P$. falciparum asexually for over one year, five were exposed to different concentrations of atovaquone, while the sixth one was cultured without drug pressure. Results revealed higher mutation rates; i.e. more single nucleotide polymorphisms (SNPs) in genes encoding cytochrome b complex (Cytbc) and multidrug resistance (MDR)associated proteins in clones cultured with drug pressure ${ }^{[13]}$. It was concluded that occurrence of gene mutation could happen within few cycles of asexual erythrocytic stages' replication ${ }^{[12]}$. In contrast to $P$. falciparum, anti-malarial drug resistance in $P$. vivax and $P$. ovale is more difficult to detect due to several reasons: 1) lower relative parasitemia; 2) difficultly to distinguish between relapse and drug resistance; and 3) confirmation with in vitro susceptibility studies is more difficult due to absence of suitable in vitro culture system, as in P. falciparum. Absence of clear molecular markers in $P$. vivax was concluded ${ }^{[14]}$.

\section{Quinolines}

These include aryl amino alcohols (quinine, mefloquine, lumefantrine, and halofantrine), 4-aminoquinolines (chloroquine, amodiaquine, piperaquine, and pyronaridine], and 8-aminoquinolines (primaquine, and tafenaquine). They act through binding with heme and inhibit hemozoin formation in food vacuoles of intra-erythrocytic stages, i.e., it interferes with parasite' detoxification (heme $\rightarrow$ hemozoin transformation ${ }^{[15]}$.

- Aryl amino alcohols: Utilizing quantitative trait loci analyses to identify genetic mechanisms associated with quinine resistance in $P$. falciparum clinical strains isolated from different areas, the investigators detected Pfmdr1, chloroquine (CQ) resistance transporter (Pfcrt) and sodium ${ }^{+} /$hydrogen $^{+}$exchanger 1 (Pfnhe-1) gene mutations. Being a transmembrane protein in the plasma membrane, NHE-1 is involved in active efflux of protons to maintain Plasmodium with neutral $\mathrm{pH}$ in response to acidification produced by anaerobic glycolysis, the main source of energy ${ }^{[16]}$. Another comprehensive analysis of Pfnhe-1 gene 
mutations in $P$. falciparum strains isolated from different areas confirmed its link with quinine resistance in vitro ${ }^{[17]}$. However, variable results concerning association of mutations in $n h e-1$ gene and quinine resistance suggested that either another gene, close to nhe-1 physical proximity, was incriminated or nhe-1 gene requires other additional genetic factors for mediating quinine resistance, e.g., adenosine triphosphate-4 (ATP4) ${ }^{[18]}$. Mefloquine (MFQ) and lumefantrine (LMF) are used as partner drugs for ART derivatives combined therapy, while MFQ is used alone as prophylactic drug. Increased Pfmdr1 copy number was associated with LMF-ART combined therapy in $P$. falciparum $^{[19]}$, and MFQ resistance in both $P$. falciparum ${ }^{[20]}$ and $P$. vivax ${ }^{[21]}$.

-4-Aminoquinolines: In vitro cross-resistance between 4-aminoquinolines and quinine was observed in several studies suggesting common genetic mechanism of cross-resistance, i.e. Pfmdr1, Pfcrt and Pfnhe-1 genes ${ }^{[22-25]}$. A MDR-associated protein (MRAP2), localized in plasma membrane was suggested as $C Q$, quinine and primaquine transporter ${ }^{[26]}$. Multiple mutations in crt gene enable Plasmodium to efflux CQ out for successful detoxification process ${ }^{[15]}$. In addition, a homolog of P-glycoprotein, localized on food vacuole membrane and encoded by mdr1 gene was suggested as a drug transporter. Mutations in $m d r 1$ gene were associated with CQ and amodiaquine resistance ${ }^{[27]}$.

In 2017, three studies were conducted in Cambodia to reveal the genomic mechanism of piperaquine (PPQ) resistance in P. falciparum clinical isolates. A GWAS identified SNPs on genes encoding MDR1, and plasmepsins II and III (aspartyl proteinases), associated with PPQ resistance ${ }^{[28]}$. Mutation in plasmepsins II encoding gene was further identified, but the mechanism of resistance was not clearly established ${ }^{[29]}$. In addition, three codons of crt gene mutations were linked with PPQ resistance ${ }^{[30]}$

- 8-Aminoquinolines: It was reported that primaquine is administered with CQ to increase its activity against CQ-resistant strain in P. falciparum $^{[31]}$, and in treatment of malaria vivax and ovale preventing relapses ${ }^{[32]}$. A GWAS was conducted in a clinical isolate from a patient with $P$. vivax relapse despite primaquine treatment, and detected mutations in several putative resistance genes, a result suggestive of no definitive genetic marker ${ }^{[33]}$.

- Atovaquone (AVQ): It is a hydroxyl-naphthoquinone developed when the outbreak of World War II caused substantial shortages in quinolines. Its mechanism of action is selective binding to Plasmodium Cytbc, a mitochondrial membrane protein responsible for maintenance of the membrane electrochemical potential $^{[34]}$. It was observed that AVQ resistance began rapidly in falciparum malaria when administred as a single agent. Malarone, an AVQ combined with anti-folate drug (proguanil), is recommended nowadays to travelers rather than patients in endemic countries due to its high $\operatorname{cost}^{[35]}$. Single mutations in the genes encoding Cytbc was observed in malarone resistance ${ }^{[36]}$.

\section{Anti-folates}

These include proguanil, and chlorproguanil that metabolize to cycloguanil and chlorcycloguanil, respectively, and both are potent inhibitors of dihydrofolate reductase (DHFR). As Plasmodium spp. rely on de novo synthesis of folate, anti-folates used include pyrimethamine, an analogue of folic acid, and sulfa drugs that block folate synthesis ${ }^{[37]}$. Interest in sulphonamide (sulfadoxine) and sulphone (dapsone) was raised when it was observed that they act as synergized drugs with DHFR inhibitors beside their direct inhibitory potency of dihydropteroate synthase $\left(\right.$ DHPS) ${ }^{[38]}$

Several studies documented mutations in genes encoding both DHFR and DHPS as markers for tracking resistance to anti-folates ${ }^{[39-41]}$. Utilizing genome analyses of field and laboratory-adapted P. falciparum strains isolated from Southeast Asia, the investigators identified an amplification surrounding the gene encoding GTP-cyclohydrolase 1 (GCH1), an enzyme in the folate biosynthesis pathway. This was explained as a compensatory mutation by the mutant $P f d h f r^{[42]}$. Another genetic study was conducted to compare between P. falciparum isolated from Thailand (common antifolates use), and Laos (rare antifolates use). Higher levels of copy number variations were identified in gch1 gene in Thailand isolates ${ }^{[43]}$.

Prolonged use of sulfadoxine-pyrimethamine (Fansidar) in P. falciparum clinical isolates from Malawi showed gene duplication in gch1 promotor, an infrequent mutation in other African countries ${ }^{[44]}$. An observational cohort study was conducted recently in Zambia investigating fansidar prophylactic efficacy in pregnant women and gene mutations associated with its resistance. As WHO-recommended, SP is administered during antenatal care in $P$. falciparum endemic areas to prevent high risk of related sequences, i.e. improving birth outcome. It was observed that $~$ one-fifth of the study population showed prophylactic failure with prevalent point mutations in the gene encoding DHPS and DHFR. Mutations showed double Pfdhp, triple Pfdhfr, as well as quintuple and sextuple mutants among fansidar-resistant isolates ${ }^{[45]}$.

\section{Artemisinin (ART) derivatives}

These include ART, artesunate, artemether, dihydro-ART, and synthetic ART compounds, e.g. 0Z439. They are short-acting anti-malarial drugs (half-life 0.5-1.5 h) that showed rapid relief, and quick clearance of parasitemia. Their mechniasm of action is inhibition of PfATP6, also known as sarco/endoplasmic reticulum membrane calcium ATPase (SERCA). The latter is involved in active transport of cytosolic free calcium concentrations into membrane-bound stores, an essential process for cellular survival ${ }^{[46]}$. Another 
study reported that ART derivatives obligate ring stages to enter a dormant phase, facilitating their clearance by the host immune system ${ }^{[47]}$. Later, it was observed that the essential factor in the efficacy of ART derivatives is the peroxide group that is cleaved by heme. This cleavage produces reactive oxy-radicals that were suggested to alkylate proteins adducting with essential molecules, causing rapid parasite death ${ }^{[48,49]}$. Subsequently, administration of ART-combined therapies was recommended, i.e., ART derivatives combined with a long-acting anti-malarial drug with a different mode of action. Six partner drugs were assigned in ART-derivatives combined therapy; mefloquine and lumefantrine (aryl aminoalcohols), amodiaquine, piperaquine and pyronaridine (4-aminoquinolines), and fansidar (anti-folate) ${ }^{[12]}$.

Emergence of resistant strains against ARTcombined therapy started since 2008 and became prevalent in Southeast Asia ${ }^{[50]}$. Clinical resistance was manifested by increased gametocytaemia with slow clearance of parasitemia suggesting that the infection requires more time for a long acting anti-malarial to complete cure. In other words, delayed clearance was attributed to the resistance gained against the partner drugs ${ }^{[51]}$. Two genes were incriminated in ART resistance; cysteine protease falcipain-2 (fp2) and Kelch-domain 13 (kelch13). A single article reported fp2 gene as genetic marker for ART resistance, and the investigators found that this mutation was not prevalent in Uganda ${ }^{[52]}$. Of note, members $(\sim 60)$ of Kelch family are proteins that have essential cellular response to oxidative stress (organizing and interacting with other proteins), i.e., a regulator of protein quality control $^{[53]}$. Mutations in Pfkelch13 gene resulted in dysregulation of phosphatidylinositol 3-kinase with increase phosphatidylinositol-3-phosphate levels conferring ART resistance ${ }^{[54]}$. Investigating kelch13 gene in $P$. falciparum isolated from patients from Asian and African countries revealed its link with ART derivatives resistance in Bangladesh ${ }^{[5]}$, China ${ }^{[56]}$ and Myanmar ${ }^{[57]}$. In contrast, its mutation was not prevalent in Africa; Uganda ${ }^{[52]}$, Senegal ${ }^{[58]}$, Kenya ${ }^{[59]}$, and $\mathrm{Mali}^{[60]}$. Interestingly, mutation' loci (codons) detected in Southeast Asia were not observed in isolates from Sub-Saharan African countries; instead the investigators detected several novel loci, but with very low frequencies ${ }^{[61]}$.

A recen study demonstrated a new mechanism of ART action when they observed that ART resistant strains with klech13 gene mutations showed altered hemoglobin catabolism and slow release of free ferriprotoporphyrin IX (FPIX). The latter is required for ART activation via increasing its toxic alkylating ability, i.e., decreased ART activation in klech13 mutant parasites. Potent inhibitory activity on hemozoin formation was suggested as another mechanism of ART action. In other words, there is FPIX abundance, and heam accumulation in sensitive strains ${ }^{[62]}$.
Another suggested mechanism of ART resistance was activation of the unfolded protein response (UPR). Utilizing population-based transcriptomic studies of 1,000 clinical strains, the investigators identified transcriptional increase of two chaperones linked to unfolded protein response (UPR); reactive oxygen species (ROS), and T-complex protein ring (TRiC). It was hypothesized that increased chaperones expression (ROS and TRiC) alleviated toxic protein aggregates in the endoplasmic reticulum and cytoplasm. Restoring endoplasmic reticulum homeostasis, i.e., maintenance of protein folding' quality control was suggested as UPR main function in stress condition ${ }^{[63]}$. On the other hand, although an orthologue of Pfkelch13 was demonstrated in $P$. vivax, no ART resistance has been reported yet ${ }^{[35]}$.

Siddiqui et al. ${ }^{[64]}$ reported that ART resistance in Southeast Asia, the hotspot of multidrug resistance, was observed with increased resistance to the partner drugs (mefloquine and piperaquine) in ART-combined therapy. High possibility of trans-continental spread of resistant strains was attributed to the rapid decline of the partner drugs' efficacy in Southeast Asia ${ }^{[65,66]}$. Resistance to ART combined therapy accompanied with emergence of klech13 gene mutations was not observed in other continental areas, e.g., Oceania, Africa, and South America. Accordingly, the reviewers ${ }^{[64]}$ warned of future trans-continental spread, and recommended frequent molecular surveillance of resistance markers to track resistant strains' origin. Worldwide antimalarial resistance network (www.wwarn.org) should be notified by the resistance markers in all surveyed localities. They also recommended triple ART combined therapy utilizing a second partner drug with different anti-malarial mechanism of action ${ }^{[64]}$.

Recent approach to identify genetic markers of ART resistance: Since reported polymorphisms in several genes were associated with a resistant phenotype, it is difficult to identify the causal genetic marker. A recent American study observed that GWASs missed functional genomics characterization to establish a certain genetic marker as a causal link between parasite genotype and phenotype ${ }^{[67]}$. Accordingly, they developed a new approach "Integrated selection of allele favored by evolution (iSAFE)" to identify favorable genetic mutations among regional population with a selective spread. The investigators supplied iSAFE system with the data obtained from both GWASs and transcriptomic studies. They establishrd two genetic markers in ART-derivatives, kelch13 gene, and gene products involved in stress response. Surprisingly, they detected favorable mutations in the gene encoding FIKK4.2, an atypical protein kinase with a possible role in host-cell remodeling in ART resistance. Mutations identified in GWASs, e.g. phosphatidylinositol-4-phosphate 5-kinase (PfPIP5K), histone acetyltransferase (PfHAT), and calcium-dependent protein kinase 5 (PfCDPK5) were not observed in iSAFE approach. Instead, they were identified as potential drug targets that required 
further validation for development of novel antimalarial drugs ${ }^{[67]}$.

\section{Antibiotics}

Antibiotics such as clindamycin, doxycycline, and tetracycline were also recommended for combined therapy with other anti-malarial drugs due to their inhibitory efficacy against protein translation inside Plasmodium apicoplast ${ }^{[68]}$. Clindamycin-resistance was linked with a point mutation in the apicoplast ribosomal RNA (23S rRNA) ${ }^{[69]}$. It was claimed that no clear markers of doxycycline and tetracyline resistance were identified so far ${ }^{[12]}$.

\section{[II] Anti-leishmnial drugs}

Drug resistance and its relations to gene mutations in leishmaniasis is a complex phenomenon of distinct genetic diversities. Similar to Plasmodium spp., Leishmania spp. have unique highly plastic genome with increasing potentiality for aneuploidy; i.e., ability to modulate gene expression (amplification or deletion), and to alter its chromosome ploidy in reaction to stress (drug exposure) ${ }^{[70]}$. This was attributed to variations in local copy numbers of specific loci, and numerous pairs of short repeats flanking groups of genes. Variable genomic flexibilities create increased transcripts number of target genes for adaptive and evolutionary DNA amplification to generate drug resistance ${ }^{[71,72]}$. Therefore, several resistance markers were investigated such as genes encoding mitochondrial

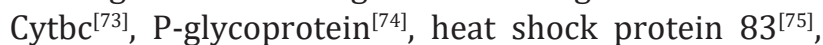
kinetoplastid membrane protein $11^{[76]}$, ornithine decarboxylase $\mathrm{e}^{[77]}$, topoisomerase $\mathrm{I}^{[78]}$, histone $\mathrm{H}_{2} \mathrm{~A}^{[79]}$, $\gamma$-glutamylcysteine synthase ${ }^{[80]}$, aquaglyceroporin-1 (AQP1) with ABC transporter MDR-assoiated protein (MRAP2) ${ }^{[81]}$, and several protein kinases ${ }^{[82]}$.

\section{Pentavalent antimonial drugs (PADs)}

They are heavy metal compounds used worldwide since the 1920s in spite of their adverse cardiac and renal toxicity. However, due to spread of drug resistance, administration was localized in Latin America and East Africa ${ }^{[83]}$. Sodium stibogluconate (SBV) achieves its function through biological reduction, i.e., by conversion to active trivalent SBIII that has an apoptopic anti-leishmanial effect ${ }^{[84]}$. Acidic $\mathrm{pH}$ and elevated temperature favor SBV reduction to stage specific SBIII, i.e., it increases in amastigotes than promastigotes rendering amastigotes more susceptible to $\mathrm{SBV}^{[85]}$. After biological reduction, it enters Leishmania via AQP1 membrane carrier, and inhibits trypanothione reductase (TR) which is a crucial survival enzyme. Trypanothione reduction is utilized by the tryparedoxin/tryparedoxin peroxidase system to neutralize ROS produced by the infected macrophages $^{[86]}$.

Several hypotheses were proposed for mechanism of PADs resistance. First, overexpression of $\mathrm{ABC}$ transporter MDR protein A2 (MRPA2, previously known as PGPA) localized in membrane vesicles close to the flagellar pocket. The MRPA2 transporter decreases drug efflux by sequestering thiol-metal conjugates in intracellular vesicles ${ }^{[87]}$. Second, diminished biological reduction decreases drug entry through overexpression of tryparedoxin peroxidase. This was associated with increased levels of reduced intracellular thiols including cysteine, glutathione, and trypanothione. The latter, a unique molecule in pathogenic trypanosomatids, has a high affinity binding with PADs forming thiol-metal conjugates. It was observed that reduced intracellular thiol levels in PADs-resistant mutants caused partial conversion of the resistance phenotype ${ }^{[88]}$. Third is the overexpression of enzymes involved in trypanothione synthesis ${ }^{[84]}$. Fourth, mutant parasites with gene encoding AQP1 and reduced AQP1 expression lead to PADs resistance ${ }^{[89]}$. Other ABC transporters were identified linked with PDAs resistance through contribution in drug efflux as thiol-metal conjugates. They included $\mathrm{ABCI} 4^{[90]}$ and ABCG $2^{[91]}$. Finally, Leishmania spp. transfected with genes encoding HSPs 70 and 90 were more resistant to SBV and this was attributed to increased tolerance against stress of drug exposure that allowed Leishmania developing more effective resistance mechanisms ${ }^{[92]}$.

Of note, host factors also contribute in PADs resistance. Some infected macrophages increased their ability to extrude PADs via overexpression of host MDR1. The surface of resistant isolates express glycans contributing to cellular events resulting in up-regulation of anti-inflammatory cytokines that provoke host MDR1 overexpression. Regarding this issue, host coinfections that necessitate administration of particular therapy e.g., anti-inflammatory drugs, to stimulate cytokines production, can diminish Leishmania sensitivity to PADs ${ }^{[93]}$.

A recent study demonstrated involvement of extensive and dynamic lipid remodeling in L. tropica PADs resistance. The investigators suggested possibe use of lipid profile as a marker to differentiate between resistant and sensitive strains. Lipidomic profile was assessed in both strains before and after drug exposure. Resistant strains showed significant downregulation of phosphatidyl-cholines (PCs) with increased levels of phosphatidyl-ethanolamines (PEs). In sensitive strains, triglycerides upregulation was observed with increased long-chain fatty acids, and decreased PEs levels. It is worth mentioning that PCs and PEs are the most abundant cell membrane components and are essential precursors of several transporters. The investigators hypothesized that PADs resistance under drug pressure might trigger phospholipid metabolism reducing $\mathrm{PCs}$ biosynthesis, as an efficient pathway to optimize the oxidative stress response against drug exposure. Further studies were recommended to validate lipid biomarkers in other Leishmania spp. ${ }^{[94]}$. 


\section{Pentamidine (PMD)}

The aromatic diamidine drug, PMD, used in treatment of African trypanosomiasis, was first used in treatment of PADs-resistant cases of leishmaniasis. Its exact mechanism of action is not well established however, several mechanisms were hypothesized. Due to its disruption of the mitochondrial inner membrane, PMD accumulates with induction of apoptosis through inhibition of respiratory chain complexes. It also causes ROS generation with increased cytosolic calcium concentration enhancing PMD cytotoxicity ${ }^{[95]}$. Interestingly, calcium channel blockers and P-glycoprotein inhibitor (verapamil) showed inhibitory potency on PMD efflux leading to accumulation of PMD in resistant clinical isolates ${ }^{[96]}$. Furthermore, PMD targeted Leishmania DNA topoisomerases (TOPs), essential enzymes required during transcription, replication, and DNA repair. This was confirmed when PMD was observed as a selective inhibitor of TOPII ${ }^{[97]}$. Regarding associated mutation, PMD resistance in Leishmania spp. was linked to $\mathrm{ABC}$ transporter P-glycoprotein, and it was termed pentamidine resistance protein $1^{[98]}$.

\section{Miltefosine (MIL)}

The major limitations of its therapeutic use as efficient anti-parasitic drug include teratogenicity, hepatic and renal toxicity side effects, high potentiality for drug resistance, and its elevated cost ${ }^{[99]}$. The anti-cancer drug, MIL, has a direct anti-leishmanial effect through interfering with phospholipids biosynthesis and alkyl-lipids metabolism. It also causes mitochondrial depolarization through its effect on cytochrome-c oxidases, and decreases ATP intracellular levels beside its effect as an apoptosis-like cell death ${ }^{[2]}$. It targets P-type ATPase Leishmania transporter responsible for phospholipids translocation within the plasma membrane. Mechanism of MIL action starts when it binds to a specific B subunit of Leishmania MIL transporter termed LROS3 ${ }^{[100]}$. Although LROS3 and its cofactor (LROS2) were linked to MIL resistance in L. donovani, scarcity of definite in vivo drug-resistant clinical isolates obstructed full identification of MIL pharmacogenetics ${ }^{[101]}$. Later, a study identified alterations in the gene encoding LROS3 and the investigators attributed these alterations to the role played by P-type ATPase Leishmania transporter in lipids arrangements within Leishmania plasma membrane ${ }^{[102]}$.

Utilizing whole-genome and RNA sequencing in MILresistant strains showed mutations in genes encoding pyridoxal kinase and $\alpha$-adaptin. Results also showed upand down-regulation of genes specifically associated with stress, and folate metabolism ${ }^{[103]}$. Overexpression of Leishmania ABC-like transporters (P-glycoproteins), including $\mathrm{ABCB} 4, \mathrm{ABCG} 4$, and $\mathrm{ABCG} 6$, reduced MIL intracellular accumulation because of increased drug efflux through Leishmania plasma membrane ${ }^{[2]}$. Lipids alterations and sterol biosynthesis in Leishmania plasma membrane controlling drug-membrane interactions, also contributed in MIL resistance in L. infantum ${ }^{[104]}$. Interestingly, several compounds were developed to overcome MIL resistance such as flavonoid derivative ${ }^{[84]}$, and 8-aminoquinoline (sitamaquine) ${ }^{105]}$ through inhibition of ABC-like transporters' overexpression.

\section{Amphotericin B (AmB)}

Besides being expensive, the main AmB side effect is acute nephrotoxicity that requires close monitoring during the first month of administration. Therefore, a liposomal formulation (LAmB) with reduced toxicity was developed ${ }^{[106]}$. The anti-fungal agent, $A m B$ is a natural product produced by Streptomyces nodosus and used as anti-leishmanial drug since the 1960s. Similar to fungi, Leishmania spp. use ergosterol as a primary membrane sterol source and AmB has high specificity to bind with plasma membrane' ergosterolrelated sterols. Of note, AmB has amphipathic nature, i.e., both hydrophilic and hydrophobic moieties. Within Leishmania plasma membrane, it spontaneously gathers with membrane lipids using its hydrophobic moiety, followed by sterols sequestration using its hydrophilic moiety. This leads to local membrane thinning that allows aqueous pores' formation for ions exchange resulting in Leishmania death ${ }^{[107]}$. Another mode of AmB action was proposed through induction of oxidative stress and Leishmania ability to prevent this oxidative damage might reduce AmB sensitivity ${ }^{[108]}$.

Sole AmB resistance was linked to mutations of the gene encoding sterol $14 \alpha$-demethylase ${ }^{[109]}$. Reports of liposomal AmB resistance in leishmaniasis are scarce since treatment failure was reported only in HIV-Leishmania coinfection in France ${ }^{[110]}$, and in an immunocompromised patient in Switzerland ${ }^{[111]}$. On the other hand, since it was observed that AmB resistant clinical isolates develop with normal ergosterol levels, an American reviewer ${ }^{[112]}$ suggested that the main mechanism for AmB resistance was by protection against the ROS-induced oxidative damage. This protection blocked the rat sarcoma virus protein (Ras)-ATPases signaling pathway trigged by aqueous pores formed within Leishmania plasma membrane, leading to increased ROS production. Functionally, Ras proteins are molecular switches controling intracellular signaling pathways, and it was hypothesized that local reduced membrane thickness caused functional activity changes of several membrane proteins, among them small lipid-anchored Ras ATPases ${ }^{[112]}$. This hypothesis was based on three evidences: First, several Ras isoforms were reported with AmB-induced apoptosis observed in oxidative damage of fungus ${ }^{[113]}$. Second, AmB as a fungicidal drug stimulates host immune response triggering toll-like receptors (TLRs) through CD14 expression leading to production of pro-inflammatory cytokines ${ }^{[114]}$, in addition to TLRs activation that was attributed to local reduced membrane thickness ${ }^{[115]}$. Third, although lack 
of ergosterol was reported in L. donovani AmB resistant clinical isolates, proteomic analysis demonstrated possession of exogenous cholesterol incorporated within their plasma membrane ${ }^{[116]}$.

\section{Paromomycin (PMM)}

It is an antibiotic orally administered for a short time and is well tolerated with rare side effects, beside its low cost. It inhibits protein synthesis through binding with $16 \mathrm{~S}$ ribosomal subunit leading to conformational RNA changes ${ }^{[117]}$. Other mechanisms of action were suggested such as modifications in membrane fluidity and lipid metabolism, decreased mitochondrial membrane potential, and respiratory dysfunction ${ }^{[18]}$. Its uptake is facilitated by binding to Leishmania surface proteins, e.g., para-flagellar rods (1D and 2D prohibitin), and a P-type ATPase transporters ${ }^{[119]}$. Its insufficient concentration requires efficient delivery system, therefore liposomal PMM formulation ${ }^{[120]}$ or albumin PMM microsphere ${ }^{[121]}$ were recommended.

Surprisingly, no gene mutations were reported associated with PMM resistance in Leishmania spp. since resistant strains demonstrated mechanisms involved in decreased PMM uptake $\mathrm{e}^{[1]}$. This caused a decreased PMM accumulation with reduction in the initial PMM binding to Leishmania surface. Accordingly, several hypotheses of decreased PMM uptake were suggested; modulation of translation rate, interaction with vesicle-mediated trafficking, increased energetic metabolism through glycolysis, and effective protection by stress-related proteins ${ }^{[2,119,122]}$.

Finally, a recent review ${ }^{[123]}$ discussed an important issue in anti-leishmanial drugs resistance due to the different genetic markers among Leishmania spp. Proteomic analyses of sensitive and resistant strains for PADs identified different overexpression levels of enzymes between L. infantum and L. braziliensis. Iron superoxide dismutase A overexpression was associated with PADs resistance in L. infantum, and not in L. braziliensis $^{[124]}$. Similar results were obtained for pteridine reductase as genetic marker in L. braziliensis, but not in $L$. infantum ${ }^{[125]}$. In addition, the Brazilian reviewers claimed that PMM sensitivity or resistance was observed among different Leishmania spp. ${ }^{[123]}$.

\section{[III] Anti-Schistosomal drugs}

The pyrazino-isoquinoline derivative, $\mathrm{PZQ}$, is the drug of choice in schistosomiasis for the last four decades. During its use, PZQ proved a safe drug inducing only mild and transient side effects. Despite forty years of administred PZQ, its exact parasite target is not established yet. Actually, PZQ causes calcium influx and disrupts schistosomes' homeostasis resulting in muscle contraction with tegmental alterations ${ }^{[126]}$. Three other hypotheses were proposed. First, upregulation of genes encoding aerobic metabolism and cytosolic calcium regulation. The obtained results suggested transcriptomic response similar to that observed during oxidative stress ${ }^{[127]}$. Second, transcriptomic analysis revealed upregulation of genes encoding MDR transporters, calcium regulation, and stress response as well as apoptosis-related proteins in juveniles compared to adults exposed to PZQ in vitro ${ }^{[128]}$. Third, impairment of reproduction and activity of sodium/ potassium-ATPase in female and male adults, was reported $^{[129]}$.

Doubtless, relying on a single drug while there is considerable concern regarding resistance development, renders rapid search for alternatives a critical issue. Although only two studies reported three schistosomiasis haematobium cases who failed to respond to PZQ treatment ${ }^{[130,131]}$, several studies observed resistance of $S$. mansoni and $S$. japonicum in field and clinical studies ${ }^{[132-135]}$. Due to absence of an exact PZQ target, its mechanism of resistance remains undetermined yet. Therefore, the reviewers ${ }^{[136]}$ claimed that since PZQ has a single drawback, i.e., inefficiency against juveniles, appearance of resistant strains could be solved. Sufficient and efficient understanding of PZQ mechanisms of both action and resistance as well as its metabolism in field studies would accelerate development of novel targets or improvement of efficacy in treatment of schistosomiasis ${ }^{[136]}$.

Recently, a systematic review published in 2020 analyzed other factors contributing to reduced PZQ efficacy ${ }^{[137]}$. The British reviewers discussed the few cases with incomplete cure after PZQ treatment that were attributed to decreased drug efficacy or emergence of resistant strains. They hypothesized that there are other factors influencing host PZQ level that participate in causing low cure rates. They concluded that host cytochrome P450 (CYP) enzymes is incriminated in PZQ reduced efficacy ascertained by three evidences. First, CYPs genetic polymorphisms are linked with inter-individual response variation to metabolism of other drugs. In other words, efficacy of drugs tested in Europe may not have similar efficacy in Africa ${ }^{[138]}$. Second, host CYPs were shown mediating PZQ metabolism ${ }^{[139]}$. Third, since CYPs are essential sites for drug-drug interactions (DIDs), and since PZQ is metabolized by several CYPs, hence DIDs within CYP pathways might lead to metabolic products accumulation, and subsequent reduction of PZQ therapeutic efficacy ${ }^{[140]}$. Drug factors also contribute to understanding the mechanism of PZQ reistance. Only PZQ (R) enantiomer has anti-schistosomal activity, while its (S) enantiomer might participitate in PZQ's side effects and resistance ${ }^{[141]}$. Based on these evidences, the British reviewers ${ }^{[137]}$ proposed host factors and PZQ formulation in PZQ incomplete cure.

\section{[IV] Anti-filarial drugs}

Lymphatic filariasis elimination relies mainly on MDA-WHO recommended regimen that was based on once-yearly administration of single doses of two drugs given together for at least 5 years to at least 
$65 \%$ of residents in the endemic area. In coinfection with onchocerciasis, ivermectin (IVM) and albendazole (ABZ) are recommended; while IVM is replaced by diethylcarbamazine (DEC) in other areas. In contrast to anti-schistosomal drugs, currently available antifilarial drugs have microfilaricidal potency with low effects on adult filarial worms ${ }^{[142]}$.

Anti-filarial drug resistance is a common phenomenon attributed to MDA programsimplemented in endemic areas. A Spanish researcher ${ }^{[143]}$ reviewed the mechanisms of drug resistance and claimed that control or elimination of lymphatic filariasis is difficult due to anti-filarial drug resistance, ineffective vector control programs and unavailability of protective vaccine candidate. The reviewer observed that MDA in endemic countries created a strong selective pressure leading to emergence of resistant strains, and subsequent unsuccessful complete treatment. Moreover, drug pressure has significant influence on genetic variation among the parasite population; i.e., an additional factor for development and spread of resistant strains. The reviewer concluded that understanding the mechanisms of drug resistance due to genetic variation is an essential step to determinate the existence of drug-resistant strains, and to search for new filarial genetic markers for drug resistance ${ }^{[143]}$.

1. Diethylcarbamazine (DEC): A piperazine derivate, DEC exerts its effects on filarial polyunsaturated fatty acids' production that block the cyclooxygenase pathway. Their cytotoxic activity produces vasoconstriction and endothelial adhesion leading to microfilaria immobilization and death ${ }^{[144]}$.

2. Albendazole (ABZ): Notably, ABZ is a broadspectrum anthelmintic drug that selectively binds to the cytoskeletal protein $\beta$-tubulin blocking microtubule matrix formation and stops cell division. It blocks glucose uptake in microfilaria and adults, leading to reduction of ATP with parasite immobilization and death. Prolonged suppression of $W$. bancrofti reproduction was also suggested as an ABZ mechanism of action ${ }^{[145]}$. Genetic variation associated with SNPs in the gene encoding $\beta$-tubulin in microfilaria-ABZresistant strains was suggested ${ }^{[146]}$.

3. Ivermectin (IVM): Although IVM is a broadspectrum nematocidal drug, its exact mechanism of action is still unknown. Because IVM in vitro effects required higher concentrations than in vivo effects, it was suggested that IVM caused reduction of excretory/ secretory proteins that modulated host immune responses in vivo ${ }^{[147]}$. Later, it was observed that IVM has a high affinity to glutamate-gated chloride channels, and neurotransmitters, causing increased cell membrane permeability that affects parasite motility and reproduction. Genomic and transcriptomic analyses of B. malayi showed expression of glutamategated chloride channel subunits in female' and to lesser extend in male' reproductive tracts as well as microfilaria embryonic stages. Accordingly, the investigators suggested sterility as IVM mechanism of action ${ }^{[148]}$. Up to date, no confirmed resistance to IVM in lymphatic filariasis was reported. However, IVM resistance associated with genetic variations in O. volvulus was observed in genes encoding MDR1 $1^{[149]}$, ABC transporter ${ }^{[150]}$, P-glycoprotein-like $\operatorname{protein}^{[151]}$, and cytochrome $\mathrm{P}^{[152]}$.

Three issues were observed in resistance to antifilarial drugs. First, spread of ABZ resistance was higher when it was combined with DEC than when combined with IVM. Accordingly, higher MDA program coverage in a population accelerated the spread of $A B Z$ resistance ${ }^{[153]}$. Second, presence of IVM resistance increased ABZ resistance rate, and vice versa ${ }^{[154]}$. Third, high genetic diversity in $W$. bancrofti populations utilizing gene encoding cytochrome oxidase subunit 1 was observed. Eleven haplotypes with several polymorphic sites were identified in 15 out of 16 strains collected from patients with lymphatic filariasis ${ }^{[155]}$.

\section{[V] Anti-toxoplasmosis drugs}

1. Combined pyrimethamine (PYR), and sulfonamides (SFDs): It was reported that PYR and SFD inhibit essential enzymes for pyrimidine biosynthesis, i.e., DHFR and DHPS, respectively. Accordingly, combined therapy has a synergistic inhibitory activity on T. gondii survival and replication. Using in vitro mutagenesis, a single point mutation detected in DHFR-thymidylate synthase encoding gene and was associated with PYR-resistant RH strain compared to types II and III ${ }^{[156]}$. Another mutation was identified in gene encoding DHPS associated with SFDs resistance using direct sequencing of PCR products ${ }^{[157]}$. In contrast, a French study investigated the previous mutations in 17 T. gondii isolates in vitro and observed variabile susceptibilities with neither clear evidence of drug resistance, nor defined mutations in the studied genes. Besides, they detected three strains resistant to SFDs, with several identical mutations in dhps gene $\mathrm{e}^{[158]}$. Another two studies denied the link between SFDs resistance and polymorphisms or overexpression in $d h f r$, dhps and $\mathrm{ABC}$ transporter genes family. They recommended further studies to investigate mechanism of SFDs resistance in toxoplasmosis and the associated gene mutations ${ }^{[159]}$. Similarly, no mutation was detected in Tgdhps gene in five samples with SFDsresistance isolated from newborns with congenital toxoplasmosis in Brazil ${ }^{[160]}$.

2. Atovaquone (AVQ): It is administered in toxoplasmosis acting against chronic bradyzoites through inhibition of mitochondrial electron transport chain. However, its administration failed to prevent toxoplasmosis in hematopoietic cell transplant recipients ${ }^{[161]}$. Similar to AVQ-resistance in anti-malarial drugs resistance, mutation in the genes encoding Cytbc was associated with AVQ resistance in T. gondii ${ }^{[162]}$. 
3. Spiramycin, clindamycin, and azithromycin: Similar to clindamycin resistance as an anti-malarial drug, resistance to these antibiotics was associated with mutation in rRNA encoding genes involved in apicoplast protein synthesis ${ }^{[163]}$.

4. Artemisinin (ART) derivatives: Similar to other apicomplexans, calcium hemostasis was suggested as the mechanism of ART action in toxoplasmosis ${ }^{[164]}$. Although they are not commonly used in treatment of toxoplasmosis, they proved effective against $T$. gondii in vitro and in vivo ${ }^{[165]}$. Mechanisms of ART derivatives' resistance was previously discussed in anti-malarial drugs.

5. Dinitroanilines: They inhibit T. gondii microtubules, and $\alpha$-tubulin point mutations were identified in resistant strains ${ }^{[166]}$.

\section{[VI] Other anti-parasitic drugs}

1. Melarsoprol (MEL): In treatment of human African trypanosomiasis (HAT), the most less toxic but with poor ability to cross the blood brain barrier (i.e. suitable for first phase) are pentamidine for HAT gambiense, and suramin (SUR) for HAT rhodesiense. For the second phase, melarsoprol (MEL) was the only drug available until the 1990s, to be later combined with nifurtimoxeflornithine therapy. Among them, MEL is the only drug with widespread drug resistance where the genetic mechanism of resistance was established ${ }^{[167]}$. It is worth noting that SUR targets glycolysis pathway, competitively inhibiting 6-phosphogluconate dehydrogenase required for pentose phosphate pathway, and impaired cell division. Multiple SUR targets might explain lack of its resistance in humans in spite of use for almost a century ${ }^{[168]}$. However, under laboratory conditions, emerging resistant strains were obtained with high expression of a variant surface glycoprotein protecting trypanosomes against hosts' immune responses ${ }^{[169]}$.

Notably, MEL is a trivalent arsenical compound intravenously administered in HAT. Due to its ability for crossing the blood brain barrier, MEL might cause a fatal reactive encephalopathy side effect $^{[170]}$. Two transporters; P2 adenosine and AQP2 were incriminated in MEL uptake that resulted in a competitive inhibitor of the trypanothione reductase. Cell lysis due to impairment in glycolytic pathway and mitosis inhibition were suggested as MEL mode of actions $^{[167]}$.

Gene encoding P2 adenosine transporter (Tbat1) showed mutations in $58 \%$ of $T$. gambiense MEL resistant isolates. However, several patients with relapse after MEL therapy had the wild-type Tbat1 gene. The investigators suggested that Tbat1 gene mutation was not the only mechanism behind MEL resistance or failure ${ }^{[171]}$. Two years later, the same investigators confirmed contribution of AQP2 transporter in P2 adenosine transporter activity ${ }^{[172]}$. Later, it was confirmed that selection for MEL resistance occurred with cross-resistance to PMD and vice versa ${ }^{[173]}$. Mutations in both transporters are responsible for low MEL uptake, and both mutations were demonstrated in MEL-PMD cross resistance in field ${ }^{[174]}$ and clinical isolates $^{[175]}$. Additionally, overexpression of the ABC transporter MDR protein A (MRPA) was found to increase MEL efflux and was postulated as mechanism of MEL resistance in vitro ${ }^{[176]}$.

2. Triclabendazole (TCBZ): It inhibits Fasciola microtubule-based processes, i.e., feeding and reproduction, through $\beta$-tubulin binding. In their review, Fairweather et al. ${ }^{[177]}$ claimed that TCBZ binds with $\beta$-tubulin at another different site than the other benzimidazoles. Because there is no reported evidence for $\beta$-tubulin mutations to date, the reviewers concluded that its mechanism of resistance is not fully understood. Accordingly, the reviewers discussed other possibilities for TCBZ resistance that altered drug uptake and/or metabolism ${ }^{[177]}$. In TCBZ resistance, investigators observed that overexpression of P-glycoprotein, a membrane transporter, reduced TCBZ intracellular concentration via drug efflux pumps. A SNP was identified in its encoding gene in resistant strains isolated from England ${ }^{[178]}$. However, this SNP was not identified from TCBZ resistant strains isolated from Australia ${ }^{[179]}$, or Latin America ${ }^{[180]}$. Increased levels of inert metabolites (TCBZ sulphoxide and sulphur dioxide) from excessive TCBZ metabolism was also observed in resistant strains ${ }^{[181]}$. Glutathione S-transferase is involved in TCBZ metabolism, and its activity was higher in TCBZ-resistant than -sensitive flukes ${ }^{[182]}$. Finally, the reviewers concluded that TCBZ resistance in $F$. hepatica is polygenic in nature. Its mechanism of resistance is much complicated due to subsequent impact of TCBZ metabolites in its mode of action. They recommended further studies to elucidate any genetic markers for TCBZ resistance ${ }^{[177]}$.

3. Metronidazole: It targets the reductive anaerobic pathways. The nitro group of MTZ is reduced by ferredoxin produced by parasites' enzymes; pyruvate ferredoxin oxidoreductase, nitroreductase 1 and thioredoxin reductase. This reduction leads to production of the active metabolite that binds to DNA macromolecules causing oxidative stress and death ${ }^{[183,184]}$. Several reasons were proposed in persistence of giardiasis, intestinal amoebiasis, and trichomoniasis in spite of MTZ treatment; drug resistance, parasite virulence, reinfection, and immunosuppressant diseases or therapy ${ }^{[185]}$. Orozco et al. ${ }^{[186]}$ reviewed MDR in amoebiasis, and it was attributed to mutation of E. histolytica P-glycoproteinlike gene. Muller et al. ${ }^{[187]}$ suggested increased Giardia tolerance to oxidative stress through upregulation of heat-shock proteins. However, it was shown that isolates of $G$. lamblia, E. histolytica and T. vaginalis had different combinations of gene mutations either 
similar to H. pylori or Bacteroides fragilis in the genes encoding enzymes involved in MTZ activation or deactivation, respectively ${ }^{[188]}$. In two Iranian studies, the investigators detected point mutation at ITS1 fragment ${ }^{[189]}$, and ferredoxin encoding gene ${ }^{[190]}$ of their T. vaginalis isolates. After discussing studies with MTZrefractory giardiasis, the reviewers ${ }^{[191]}$ claimed that mechanisms underlying MTZ resistance are not clearly understood yet. Accordingly, they recommended further studies to establish the molecular and/or genetic basis for MTZ resistance in clinical isolates ${ }^{[191]}$. On the other hand, an American study conducted recently reported that although $T$. vaginalis virus was detected in $40 \%$ of their study population, it had no influence in clinical manifestations, reinfections and MTZ resistance ${ }^{[192]}$. In addition, based on the results obtained from two recently conducted studies ${ }^{[193,194]}$, German reviewers ${ }^{[195]}$ attributed MTZ resistance to over-expression of various effector molecules without specific target gene mutations, i.e., epigenetic or posttranslational modifications without a recognized pattern in proteomic assays. They hypothesized that these modifications had essential roles in the parasite DNA with more significant effects than mutational base exchange ${ }^{[195]}$.

\section{CONCLUDING REMARKS}

1. Emergence of drug resistance is a multi-factorial phenomenon. Ability of certain strains for gene mutations is the main factor. Targeting nonessential parasite molecules, poor pharmacokinetic properties, and quality (falsified drugs) are drug factors. Unsuccessful treatment compliance (pharmacogenetics), immune status and coinfections are the host factors. Environmental factors facilitate spread of resistant strains (under drug pressure) to new geographical endemic area.

2. Genetic mechanism of drug resistance arises early with monotherapy, drugs with fast action, as well as drugs acting on a single target. Combined therapy with different mechanisms of action would decrease emergence of drug resistance.

3. Molecular genetic markers are utilized to screen for emergence of drug resistance. Only P. falciparum and Leishmania spp. have unique plastic genome encoding multiple transporters with high potentiality to aneuploidy, and gene expression modulation (gene amplification) in response to drug exposure. Hence, anti-malarial and anti-leishmanial drugs resistance are associated with established definitive genetic markers.

4. All quinolones resistance, except for atovaquone, are associated with gene mutations in the gene encoding transmembrane proteins ( $m d r 1, c r t$ and nhe-1). Atovaquone is associated with Cytbc, and anti-folates with PfDHFR, and PfDHPS encoding genes. Resistance to ART derivatives is linked either to mutation in kelch13 gene or upregulation of unfolded protein response.
5. In anti-leishmanial drugs, $A B C$ transporters were linked with antimonial drugs (MDR protein A2, and AQP1), pentamidine (P-glycoprotein), and miltefosine (P-glycoprotein-like transporter, ROS3). Resistance to AmB is not common and attributed to Leishmania protection against the ROS-induced oxidative damage. Similarly, paromomycin (PMM) resistant strains showed mechanisms involved in decreased PMM uptake due to effective protection by stress-related proteins.

6. In contrast, neither anti-schistosomal nor antifilarial drugs are associated with genetic markers. Host cytochrome P450 (CYP) enzymes, and drug formulations are incriminated in PZQ reduced efficacy. In the latter, MDA created a strong selective pressure with a significant influence on development and spread of resistant strains. In $O$. volvulus, IVM resistance was associated with several genetic variations, e.g., MDR1, ABC transporter, and P-glycoprotein-like protein.

7. No established genetic markers were reported also for anti-toxoplasmosis drugs however, several single point mutations were identified. They included DHFR (pyrimethamine), DHPS (sulfonamides), Cytbc (Atovaquone), rRNA (clindamycin), and Kelch13 (ART derivatives) encoding genes.

8. In African trypanosomiasis, $\mathrm{ABC}$ transporters (P2 adenosine, $\mathrm{AQP} 2$, and MDR protein $\mathrm{A}$ ) are involved in increasing MEL efflux and decrease its efficacy.

9. Mechanisms of triclabendazole resistance in treatment of hepatic flukes and metronidazole in treatment of giardiasis, amoebiasis and trichomoniasis are much complicated. Subsequent influence of TCBZ metabolites in its mode of action was suggested for triclabendazole resistance, while post-translational modifications of various effector molecules without a specific point gene mutation was suggested for metronidazole.

Conflict of interest: The author claims neither actual nor potential conflict of interest with any organization that could influence this work.

Funding statement: No funds received.

\section{REFERENCES}

1. Capela R, Moreira R, Lopes F. An overview of drug resistance in protozoal diseases. Int J Mol Sci 2019; 20(22):5748.

2. Ponte-Sucre A, Gamarro F, Dujardin J-C, Barrett MP, López-Vélez R, Raquel García-Hernández R, et al. Drug resistance and treatment failure in leishmaniasis: A $21^{\text {st }}$ century challenge. PLoS Negl Trop Dis 2017; 11(12):e0006052.

3. Hendrickx S, Guerin PJ, Caljon G, Croft SL, Maes L. Evaluating drug resistance in visceral leishmaniasis: The challenges. Parasitology 2018; 145(4):453-463.

4. Anderson T, Nkhoma S, Ecker A, Fidock D. How can we identify parasite genes that underlie anti-malarial 
drug resistance? Pharmacogenomics 2011; 12(1):5985.

5. Abaza SM, El-Tonsy MS. Gene mutations in parasitic diseases. Part II. Parasite gene mutations. PUJ 2017; 10(1\&2):4-22.

6. Ariey F, Witkowski B, Amaratunga C, Beghain J, Langlois A-C, Khim N, et al. A molecular marker of artemisinin resistant Plasmodium falciparum malaria. Nature 2014; 505:50-55.

7. Babiker HA, Gadalla AA, Ranford-Cartwright LC. The role of asymptomatic $P$. falciparum parasitaemia in the evolution of anti-malarial drug resistance in areas of seasonal transmission. Drug Resist Updat 2013; 16:1-9.

8. World Health Organization. Report on antimalarial drug efficacy, resistance and response: 10 years of surveillance (2010-2019); 2020; https://www.who. int/ publications/i/item/9789240012813. Last update 19.11.2020.

9. Picot S, Olliaro P, de Monbrison F, Bienvenu AL, Price RN, Ringwald P. A systematic review and meta-analysis of evidence for correlation between molecular markers of parasite resistance and treatment outcome in falciparum malaria. Malar J 2009; 8:89.

10. McCollum AM, Schneider KA, Griffing SM, Zhou Z, Kariuki S, Ter-Kuile $\mathrm{F}$ et al. Differences in selective pressure on dhps and dhfr drug resistant mutations in western Kenya. Malar J 2012; 11:77.

11. Sharma YD. Genetic alteration in drug resistance markers of Plasmodium falciparum. Indian J Med Res 2005; 121(1):13-22.

12. Cowell AN, Winzeler EA. The genomic architecture of antimalarial drug resistance. Brief Funct Genomics 2019; 18(5):314-328.

13. Bopp SE, Manary MJ, Bright AT, Johnston GL, Dharia NV, Luna FL, et al. Mitotic evolution of Plasmodium falciparum shows a stable core genome but recombination in antigen families. PLoS Genet 2013; 9:e1003293.

14. Baird JK. Resistance to therapies for infection by Plasmodium vivax. Clin Microbiol Rev 2009; 22:508-534.

15. Ross LS, Dhingra SK, Mok S, Yeo T, Wicht KJ, Kumpornsin $\mathrm{K}$, et al. Emerging Southeast Asian PfCRT mutations confer Plasmodium falciparum resistance to the firstline anti-malarial piperaquine. Nat Commun 2018; 9:13.

16. Ferdig MT, Cooper RA, Mu J, Deng B, Joy DA, Su XZ, et al. Dissecting the loci of low-level quinine resistance in malaria parasites. Mol Microbiol 2004; 52:985-997.

17. Menard D, Andriantsoanirina V, Khim N, Ratsimbasoa A, Witkowski B, Benedet C et al. Global analysis of Plasmodium falciparum $\mathrm{Na}^{+} / \mathrm{H}^{+}$exchanger (Pfnhe-1) allele polymorphism and its usefulness as a marker of in vitro resistance to quinine. Int J Parasitol Drugs Drug Resist 2013; 3:8-19.

18. Andriantsoanirina V, Menard D, Rabearimanana $S$, Hubert V, Bouchier C, Tichit M, et al. Association of microsatellite variations of Plasmodium falciparum $\mathrm{Na}^{+} / \mathrm{H}^{+}$exchanger (Pfnhe-1) gene with reduced in vitro susceptibility to quinine: Lack of confirmation in clinical isolates from Africa. Am J Trop Med Hyg 2010; 82:782-787.
19. Price RN, Uhlemann AC, Brockman A, McGready R, Ashley E, Phaipun L, et al. Mefloquine resistance in Plasmodium falciparum and increased Pfmdr1 gene copy number. Lancet 2004; 364:438-447.

20. Price RN, Uhlemann A-C, van Vugt $M$, Brockman A, Hutagalung R, Nair S, et al. Molecular and pharmacological determinants of the therapeutic response to artemether-lumefantrine in multidrugresistant Plasmodium falciparum malaria. Clin Infect Dis 2006; 42:1570-1577.

21. Auburn S, Serre D, Pearson RD, Amato R, Sriprawat K, To $\mathrm{S}$, et al. Genomic analysis reveals a common breakpoint in amplifications of the Plasmodium vivax multidrug resistance 1 locus in Thailand. J Infect Dis 2016; 214:1235-1242.

22. Johnson DJ, Fidock DA, Mungthin M, Lakshmanan V, Sidhu ABS, Bray PG, et al. Evidence for a central role for PfCRT in conferring Plasmodium falciparum resistance to diverse antimalarial agents. Mol Cell 2004; 15:867877.

23. Duraisingh MT, Cowman AF. Contribution of the Pfmdr1 gene to antimalarial drug-resistance. Acta Trop 2005; 94:181-190.

24. Sidhu AB, Valderramos SG. Fidock DA. Pfmdr1 mutations contribute to quinine resistance and enhance mefloquine and artemisinin sensitivity in Plasmodium falciparum. Mol Microbiol 2005; 57:913-926.

25. Wurtz N, Fall B, Pascual A, Fall M, Baret E, Camara C, et al. Role of Pfmdr1 in in vitro Plasmodium falciparum susceptibility to chloroquine, quinine, monodesethylamodiaquine, mefloquine, lumefantrine, and dihydroartemisinin. Antimicrob Agents Chemother 2014; 58:7032-7040.

26. Veiga MI, Osorio NS, Ferreira PE, Franzen O, Dahlstrom $\mathrm{S}$, Lum JK, et al. Complex polymorphisms in the Plasmodium falciparum multidrug resistance protein 2 gene and its contribution to antimalarial response. Antimicrob Agents Chemother 2014; 58:7390-7397.

27. Xu C, Wei QK, Yin K, Sun H, Li J, Xiao T, et al. Surveillance of antimalarial resistance Pfcrt, Pfmdr1, and Pfkelch13 polymorphisms in African Plasmodium falciparum imported to Shandong Province, China. Sci Rep 2018; 8:9.

28. Amato R, Lim P, Miotto O, Amaratunga C, Dek D, Pearson RD et al. Genetic markers associated with dihydroartemisinin-piperaquine failure in Plasmodium falciparum malaria in Cambodia: A genotype-phenotype association study. Lancet Infect Dis 2017; 17:164-173.

29. Witkowski B, Duru V, Khim N, Ross LS, Saintpierre B, Beghain J, et al. A surrogate marker of piperaquineresistant Plasmodium falciparum malaria: A phenotypegenotype association study. Lancet Infect Dis 2017; 17:174-183.

30. Agrawal S, Moser KA, Morton L, Cummings MP, Parihar A, Dwivedi A, et al. Association of a novel mutation in the Plasmodium falciparum chloroquine resistance transporter with decreased piperaquine sensitivity. J Infect Dis 2017; 216:468-476.

31. Bray PG, Deed S, Fox E, Kalkanidis M, Mungthin M, Deady LW, et al. Primaquine synergizes the activity of 
chloroquine against chloroquine-resistant $P$. falciparum. Biochem Pharmacol 2005; 70:1158-1166.

32. Chu CS, White NJ. Management of relapsing Plasmodium vivax malaria. Expert Rev Anti Infect Ther 2016; 14:885900.

33. Bright AT, Alenazi T, Shokoples S, Tarning J, Paganotti $\mathrm{GM}$, White NJ, et al. Genetic analysis of primaquine tolerance in a patient with relapsing vivax malaria. Emerg Infect Dis 2013; 19:802-805.

34. Nixon GL, Moss DM, Shone AE, Lalloo DG, Fisher N, O'Neill PM, et al. Antimalarial pharmacology and therapeutics of atovaquone. J Antimicrob Chemother 2013; 68:977-985.

35. Haldar K, Bhattacharjee S, Safeukui I. Drug resistance in Plasmodium. Nat Rev Microbiol 2018; 16(3):156-170.

36. Staines HM, Burrow R, Teo BHY, Ster IC, Kremsner PG, Krishna S. Clinical implications of Plasmodium resistance to atovaquone/proguanil: A systematic review and meta-analysis. J Antimicrob Chemother 2018; 73:581-595.

37. Nzila A. Antifolates: Pyrimethamine, Proguanil, Sulphadoxine and Dapsone. In: Krishna S, Staines HM (Editors). Treatment and Prevention of Malaria. $1^{\text {st }}$ edition, Springer Science \& Business Media; Berlin, Germany: 2012.

38. Verhoef H, Veenemans J, Mwangi MN, Prentice AM. Safety and benefits of interventions to increase folate status in malaria-endemic areas. Br J Haematol 2017; 177:905-918.

39. Cui LW, Mharakurwa S, Ndiaye D, Rathod PK, Rosenthal PJ. Antimalarial drug resistance: Literature review and activities and findings of the ICEMR network. Am J Trop Med Hyg 2015; 93:57-68.

40. Antony HA, Parija SC. Antimalarial drug resistance: An overview. Trop Parasitol 2016; 6:30-41.

41. Abugri J, Ansah F, Asante KP, Opoku CN, Amenga-Etego LA, Awandare GA. Prevalence of chloroquine and antifolate drug resistance alleles in clinical isolates from three Plasmodium falciparum areas in Ghana. AAS Open Res 2018; 1:1-11.

42. Dittrich S, Mitchell SL, Blagborough AM, Wang Q Wang P, Sims PFG, et al. An atypical orthologue of 6-pyruvoyltetrahydropterin synthase can provide the missing link in the folate biosynthesis pathway of malaria parasites. Mol Microbiol 2008; 67:609-618.

43. Nair S, Miller B, Barends M, Jaidee A, Patel J, Mayxay $\mathrm{M}$, et al. Adaptive copy number evolution in malaria parasites. PLoS Genet 2008; 4:e1000243.

44. Ravenhall M, Benavente ED, Mipando M, Jensen ATR, Sutherland CJ, Roper C, et al. Characterizing the impact of sustained sulfadoxine/pyrimethamine use upon the Plasmodium falciparum population in Malawi. Malar J 2016; 15:575.

45. Chaponda EB, Mharakurwa S, Michelo C, Bruce J, Chandramoha D, Matthew Chico R. Sulfadoxinepyrimethamine parasitological efficacy against Plasmodium falciparum among pregnant women and molecular markers of resistance in Zambia: An observational cohort study. Malar J 2021; 20(1):61.
46. Eckstein-Ludwig U, Webb R, Van Goethem I, East JM, Lee AG, Kimura M, et al. Artemisinins target the SERCA of Plasmodium falciparum. Nature 2003; 424(6951):957.

47. Witkowski B, Lelievre J, Barragan MJ, Laurent V, Su $\mathrm{XZ}$, Berry A et al. Increased tolerance to artemisinin in Plasmodium falciparum is mediated by a quiescence mechanism. Antimicrob Agents Chemother 2010; 54:1872-1877.

48. Li Y. Qinghaosu (artemisinin): Chemistry and pharmacology. Acta Pharmacol Sin 2012; 33:11411146.

49. Ismail HM, BartonVE, Panchana M, Charoensutthivarakul S, Biagini GA, Ward SA, et al. A Click chemistry-based proteomic approach reveals that 1,2,4-trioxolane and artemisinin anti-malarials share a common protein alkylation profile. Angew Chemie Int Ed 2016; 55:64016405.

50. World Health Organization. Guidelines for the Treatment of Malaria, $3^{\text {rd }}$ edition, WHO; Geneva, Switzerland; 2015.

51. Chookajorn T. How to combat emerging artemisinin resistance: Lessons from "The Three Little Pigs" PLoS Path 2018; 14:8.

52. Conrad MD, Bigira V, Kapisi J, Muhindo M, Kamya MR, Havlir DV et al. Polymorphisms in K13 and falcipain-2 associated with artemisinin resistance are not prevalent in Plasmodium falciparum isolated from Ugandan children. PLoS One 2014; 9(8):e105690.

53. Gupta VA, Beggs AH. Kelch proteins: Emerging roles in skeletal muscle development and diseases. Skelet Muscle 2014; 4, 11.

54. Mbengue A, Bhattacharjee S, Pandharkar T, Liu H, Estiu G, Stahelin RV, et al. A molecular mechanism of artemisinin resistance in Plasmodium falciparum malaria. Nature 2015; 520:683-687.

55. Mohon AN, Alam MS, Bayih AG, Folefoc A, Shahinas D, Haque R et al. Mutations in Plasmodium falciparum K13 propeller gene from Bangladesh (2009-2013). Malar J 2014; 13:431.

56. Huang F, Takala-Harrison S, Jacob CG, Liu H, Sun X, Yang $\mathrm{H}$, et al. A single mutation in $\mathrm{K} 13$ predominates in Southern China and is associated with delayed clearance of Plasmodium falciparum following artemisinin treatment. J Infect Dis 2015; 212(10):1629-1635.

57. Nyunt MH, Hlaing T, Oo HW, Tin-Oo LL, Phway HP, Wang $\mathrm{B}$, et al. Molecular assessment of artemisinin resistance markers, polymorphisms in the $\mathrm{k} 13$ propeller, and a multidrug-resistance gene in the eastern and western border areas of Myanmar. Clin Infect Dis 2015; 60(8):1208-1215.

58. Torrentino-Madamet M, Fall B, Benoit N, Camara C, Amalvict R, Fall M, et al. Limited polymorphisms in k13 gene in Plasmodium falciparum isolates from Dakar, Senegal in 2012-2013. Malar J 2014; 13:472.

59. Isozumi R, Uemura H, Kimata I, Ichinose Y, Logedi J, Omar AH, et al. Novel mutations in K13 propeller gene of artemisinin-resistant Plasmodium falciparum. Emerg Infect Dis 2015; 21:490-492.

60. Ouattara A, Kone A, Adams M, Fofana B, Maiga AW, Hampton, $\mathrm{S}$ et al. Polymorphisms in the K13-propeller 
gene in artemisinin-susceptible Plasmodium falciparum parasites from Bougoula-Hameau and Bandiagara, Mali. Am J Trop Med Hyg 2015; 92(6):1202-1206.

61. Taylor SM, Parobek CM, DeConti DK, Kayentao K, Coulibaly SO, Greenwood BM, et al. Absence of putative artemisinin resistance mutations among Plasmodium falciparum in Sub-Saharan Africa: A molecular epidemiologic study. J Infect Dis; 2015; 211(5):680-688.

62. Ribbiso KA, Heller LE, Taye A, Julian E, Willems AV, Roepe PD. Artemisinin-based drugs target the Plasmodium falciparum heme detoxification pathway. Antimicrob Agents Chemother 2021; 65(4):e02137-20.

63. Mok S, Ashley EA, Ferreira PE, Zhu L, Lin Z, Yeo T, et al. Population transcriptomics of human malaria parasites reveals the mechanism of artemisinin resistance. Science 2015; 347:431-435.

64. Siddiqui FA, Liang X, Cui L. Plasmodium falciparum resistance to ACTs: Emergence, mechanisms, and outlook. Int J Parasitol Drugs Drug Resist 2021; 16:102118.

65. Hamilton WL, Amato R, van der Pluijm RW, Jacob CG, Quang HH, Thuy-Nhien NT, et al. Evolution and expansion of multidrug-resistant malaria in Southeast Asia: A genomic epidemiology study. Lancet Infect Dis 2019; 19:943-951.

66. Imwong M, Dhorda M, Myo-Tun K, Thu AM, Phyo AP, Proux S, et al. Molecular epidemiology of resistance to antimalarial drugs in the Greater Mekong subregion: An observational study. Lancet Infect Dis 2020; 20:14701480.

67. Oberstaller J, Zoungrana L, Bannerman CD, Jahangiri S, Dwivedi A, Silva JC, et al. Integration of population and functional genomics to understand mechanisms of artemisinin resistance in Plasmodium falciparum. Int J Parasitol Drugs Drug Resist 2021; 16:119-128.

68. Blascod DL, Wittyd MJ, Doninid C, Taylor D, Abay E, Njoroge M, et al. UCT943: A next generation Plasmodium falciparum PI4K inhibitor preclinical candidate for the treatment of malaria. Antimicrob Agents Chemother 2018; 62(9):e00012-18.

69. Dharia NV, Plouffe D, Bopp SE, González-Páez GE, Lucas C, Salas C, et al. Genome scanning of Amazonian Plasmodium falciparum shows subtelomeric instability and clindamycin-resistant parasites. Genome Res 2010; 20:1534-1544.

70. Leprohon P, Legare D, Raymond F, Madore E, Hardiman G, Corbeil J et al. Gene expression modulation is associated with gene amplification, supernumerary chromosomes and chromosome loss in antimony-resistant Leishmania infantum. Nucleic Acids Res 2009; 37:1387-1399.

71. Ubeda JM, Raymond F, Mukherjee A, Plourde M, Gingras H, Roy G, et al. Genome-wide stochastic adaptive DNA amplification at direct and inverted DNA repeats in the parasite Leishmania. PLoS Biol 2014; 12(5):e1001868.

72. Laffitte MN, Leprohon P, Papadopoulou B, Ouellette M. Plasticity of the Leishmania genome leading to gene copy number variations and drug resistance. F1000Res 2016; 5:2350.

73. Schnaufer A, Sbicego S, Blum B. Antimycin A resistance in a mutant Leishmania tarentolae strain is correlated to a point mutation in the mitochondrial apocytochrome $b$ gene. Curr Genet 2000; 37(4):234-241.

74. Anacleto C, Abdo MC, Ferreira AV, Murta SM, Romanha AJ, Fernandes AP et al. Structural and functional analysis of an amplification containing a PGPA gene in a glucantime-resistant Leishmania (Viannia) guyanensis cell line. Parasitol Res 2003; 90(2): 110-118.

75. Vergnes B, Gourbal B, Girard I, Sundar S, Drummelsmith J, Ouellette M. A proteomics screen implicates HSP83 and a small kinetoplastid calpain-related protein in drug resistance in Leishmania donovani clinical field isolates by modulating drug-induced programmed cell death. Mol Cell Proteomics 2007; 6:88-101.

76. El FK, Drummelsmith J, Roy G, Jardim A, Ouellette M. Down regulation of KMP-11 in Leishmania infantum axenic antimony resistant amastigotes as revealed by a proteomic screen. Exp Parasitol 2009; 123:51-57.

77. Mukherjee A, Padmanabhan PK, Singh S, Roy G, Girard I, Chatterjee $\mathrm{M}$, et al. Role of ABC transporter MRPA, gamma-glutamylcysteine synthetase and ornithine decarboxylase in natural antimony-resistant isolates of Leishmania donovani. J Antimicrob Chemother 2009; 59:204-211.

78. Roy A, BoseDasgupta S, Ganguly A, Jaisankar P, Majumder HK. Topoisomerase I gene mutations at F270 in the large subunit and N184 in the small subunit contribute to the resistance mechanism of the unicellular parasite Leishmania donovani towards 3,3'-diindolylmethane. Antimicrob Agents Chemother 2009; 53(6):2589-2598.

79. Singh R, Kumar D, Duncan RC, Nakhasi HL, Salotra P. Overexpression of histone $\mathrm{H} 2 \mathrm{~A}$ modulates drug susceptibility in Leishmania parasites. Int J Antimicrob Agents 2010; 36:50-57.

80. Ashutosh, Garg M, Sundar S, Duncan R, Nakhasi HL, Goyal N. Downregulation of mitogen-activated protein kinase 1 of Leishmania donovani field isolates is associated with antimony resistance. Antimicrob Agents Chemother 2012; 56:518-525.

81. Kumar D, Singh R, Bhandari V, Kulshrestha A, Negi NS, Salotra P. Biomarkers of antimony resistance: Need for expression analysis of multiple genes to distinguish resistance phenotype in clinical isolates of Leishmania donovani. Parasitol Res 2012; 111:223-230.

82. Kazemi-Rad E, Mohebali M, Khadem-Erfan MB, Saffari M, Raoofian R, Hajjaran $\mathrm{H}$, et al. Identification of antimony resistance markers in Leishmania tropica field isolates through a cDNA-AFLP approach. Exp Parasitol 2013; 135:344-349.

83. Croft SL, Olliaro P. Leishmaniasis chemotherapy: Challenges and opportunities. Clin Microbiol Infect 2011; 17(10):1478-1483.

84. Maltezou HC. Drug resistance in visceral leishmaniasis. J Biomed Biotechnol 2010; 2010:617521.

85. Pund S, Joshi A. Nanoarchitectures for neglected tropical protozoal diseases: Challenges and state of the art. In: Grumezescu AM (Editor), Nano-and Microscale Drug Delivery Systems. $1^{\text {st }}$ edition, Elsevier; Amsterdam, The Netherlands; 2017.

86. Turcano L, Torrente E, Missineo A, Andreini M, Gramiccia M, Di Muccio T, et al. Identification and binding mode of 
a novel Leishmania trypanothione reductase inhibitor from high throughput screening. PLoS Negl Trop Dis 2018; $12: 21$.

87. Ashutosh, Sundar S, Goyal N. Molecular mechanisms of antimony resistance in Leishmania. J Med Microbiol 2007; 56(2):143-153.

88. Wyllie S, Vickers TJ, Fairlamb AH. Roles of trypanothione S-transferase and tryparedoxin peroxidase in resistance to antimonials. Antimicrob Agents Chemother 2008; 52(4):1359-1365.

89. Mandal S, Maharjan M, Singh S, Chatterjee M, Madhubala R. Assessing aquaglyceroporin gene status and expression profile in antimony-susceptible and -resistant clinical isolates of Leishmania donovani from India. J Antimicrob Chemother 2010; 65(3):496-507.

90. Manzano JI, García-Hernández R, Castanys S, Gamarro F. A new ABC half-transporter in Leishmania major is involved in resistance to antimony. Antimicrob Agents Chemother 2013; 57(8):3719-3730.

91. Perea A, Manzano JI, Castanys S, Gamarro F. The LBCG2 transporter from the protozoan parasite Leishmania is involved in antimony resistance. Antimicrob Agents Chemother 2016; 60(6):3489-3496.

92. Kaur P, Garg M, Hombach-Barrigah A, Clos J, Goyal N. MAPK1 of Leishmania donovani interacts and phosphorylates HSP70 and HSP90 subunits of foldosome complex. Sci Rep 2017; 7:11.

93. Mukherjee B, Mukhopadhyay R, Bannerjee B, Chowdhury $\mathrm{S}$, Mukherjee S, Naskar K, et al. Antimony-resistant but not antimony-sensitive Leishmania donovani upregulates host IL-10 to overexpress multidrug-resistant protein 1. Proc Nat Acad Sci USA 2013; 110:E575-E582.

94. Gutierrez-Guarnizo SA, Tikhonova EB, ZabetMoghaddam M, Zhang K, Muskus C, Karamyshev AL, et al. Drug-induced lipid remodeling in Leishmania parasites. Microorganisms 2021; 9(4):790.

95. Mehta A, Shaha C. Apoptotic death in Leishmania donovani promastigotes in response to respiratory chain inhibition: Complex II inhibition results in increased pentamidine cytotoxicity. J Biol Chem 2004; 279:11798-11813.

96. Basselin M, Denise H, Coombs GH, Barrett MP. Resistance to pentamidine in Leishmania mexicana involves exclusion of the drug from the mitochondrion. Antimicrob Agents Chemother 2002; 46:3731-3738.

97. Cortazar TM, Coombs GH, Walker J. Leishmania panamensis: Comparative inhibition of nuclear DNA topoisomerase II enzymes from promastigotes and human macrophages reveals anti-parasite selectivity of fluoroquinolones, flavonoids and pentamidine. Exp Parasitol 2007; 116:475-482.

98. Coelho AC, Beverley SM, Cotrim PC. Functional genetic identification of PRP1, an ABC transporter superfamily member conferring pentamidine resistance in Leishmania major. Mol Biochem Parasitol 2003; 130(2):83-90.

99. Nagle AS, Khare S, Kumar AB, Supek F, Buchynskyy A, Mathison CJN, et al. Recent developments in drug discovery for leishmaniasis and human African trypanosomiasis. Chem Rev 2014; 114:11305-11347.
100.Perez-Victoria FJ, Sanchez-Canete MP, Castanys S, Gamarro F. Phospholipid translocation and miltefosine potency require both $L$. donovani miltefosine transporter and the new protein LdRos3 in Leishmania parasites. J Biol Chem 2006; 281:23766-23775.

101. Rijal S, Ostyn B, Uranw S, Rai K, Bhattarai NR, Dorlo TP, et al. Increasing failure of miltefosine in the treatment of kala-azar in Nepal and the potential role of parasite drug resistance, reinfection, or noncompliance. Clin Infect Dis 2013; 56:1530-1538.

102. Fernandez-Prada C, Vincent IM, Brotherton MC, Roberts M, Roy G, Rivas L, et al. Different mutations in a P-type ATPase transporter in Leishmania parasites are associated with cross-resistance to two leading drugs by distinct mechanisms. PLoS Negl Trop Dis 2016; 10(12):e0005171.

103. Kulshrestha A, Sharma V, Singh R, Salotra P. Comparative transcript expression analysis of miltefosine-sensitive and miltefosine-resistant Leishmania donovani. Parasitol Res 2014; 113:1171-1184.

104.Armitage EG, Alqaisi AQI, Godzien J, Pena I, Mbekeani AJ, Alonso-Herranz V, et al. Complex interplay between sphingolipid and sterol metabolism revealed by perturbations to the Leishmania metabolome caused by miltefosine. Antimicrob Agents Chemother 2018; 62:12.

105.Perez-Victoria JM, Bavchvarov BI, Torrecillas IR, Martinez-Garcia M, Lopez-Martin C, Campillo M, et al. Sitamaquine overcomes $\mathrm{ABC}$-mediated resistance to miltefosine and antimony in Leishmania. Antimicrob Agents Chemother 2011; 55:3838-3844.

106. Meyerhoff A. U.S. Food and Drug Administration approval of AmBisome (liposomal amphotericin B) for treatment of visceral leishmaniasis. Clin Infect Dis 1999; 28(1):42-48.

107.Lemke A, Kiderlen AF, Kayser O. Amphotericin B. Appl Microbiol Biotechnol 2005; 68(2):151-162.

108. Brotherton MC, Bourassa S, Légaré D, Poirier GG, Droit A, Ouellette M. Quantitative proteomic analysis of amphotericin B resistance in Leishmania infantum. Int J Parasitol Drugs Drug Resist 2014; 4(2):126-132.

109. Mwenechanya R, Kovářová J, Dickens NJ, Mudaliar M, Herzyk P, Vincent IM, et al. Sterol $14 \alpha$-demethylase mutation leads to amphotericin $B$ resistance in Leishmania mexicana. PLoS Negl Trop Dis 2017; 11(6):e0005649.

110. Morizot G, Jouffroy R, Faye A, Chabert P, Belhouari K, Calin $\mathrm{R}$, et al. Antimony to cure visceral leishmaniasis unresponsive to liposomal amphotericin B. PLoS Negl Trop Dis 2016; 10(1):e0004304.

111.Eichenberger A, Buechi AE, Neumayr A, Hatz C, Rauch A, Huguenot M, et al. A severe case of visceral leishmaniasis and liposomal amphotericin B treatment failure in an immunosuppressed patient 15 years after exposure. BMC Infect Dis 2017; 17(1):81.

112. Cohen BE. The role of signaling via aqueous pore formation in resistance responses to Amphotericin B. Antimicrob Agents Chemother 2016; 60(9):5122-5129.

113. Phillips AJ, Crowe JD, Ramsdale M. Ras pathway signaling accelerates programmed cell death in the 
pathogenic fungus Candida albicans. Proc Natl Acad Sci USA 2006; 103:726-731.

114. Razonable RR, Henault M, Lee LN, Laethem C, Johnston $\mathrm{PA}$, Watson HL, et al. Secretion of pro-inflammatory cytokines and chemokines during amphotericin B exposure is mediated by co-activation of toll-like receptors 1 and 2. Antimicrob Agents Chemother 2005; 49:1617-1621.

115. Shatursky OY, Romanenko OV, Himmelreich NH. Long open amphotericin channels revealed in cholesterolcontaining phospholipid membranes are blocked by thiazole derivative. J Membr Biol 2014; 247:211-229.

116. Purkait B, Kumar A, Nandi N, Sardar AH, Das S, Kumar $\mathrm{S}$, et al. Mechanism of amphotericin B resistance in clinical isolates of Leishmania donovani. Antimicrob Agents Chemother 2012; 56:1031-1041.

117. Wiwanitkit V. Interest in paromomycin for the treatment of visceral leishmaniasis (kala-azar). Ther Clin Risk Manag 2012; 8:323-328.

118. Fernandez MM, Malchiodi EL, Algranati ID. Differential effects of paromomycin on ribosomes of Leishmania mexicana and mammalian cells. Antimicrob Agents Chemother 2011; 55:86-93.

119. Légaré D, Ouellette M. Drug resistance in Leishmania. In: Gotte MB, Matlashewski A, Wainberg G, Mark A, Donald $S$ (Editors), Handbook of Antimicrobial Resistance; Springer; New York, NY, USA: 2017. pp. 313-341.

120. Banerjee A, De M, Ali N. Combination therapy with paromomycin-associated stearylamine-bearing liposomes cures experimental visceral leishmaniasis through Th1-biased immunomodulation. Antimicrob Agents Chemother 2011; 55:1661-1670.

121. Khan W, Sharma SS, Kumar N. Bioanalytical method development, pharmacokinetics, and toxicity studies of paromomycin and paromomycin loaded in albumin microspheres. Drug Test Anal 2013; 5:453-460.

122.Jhingran A, Chawla B, Saxena S, Barrett MP, Madhubala R. Paromomycin: Uptake and resistance in Leishmania donovani. Mol Biochem Parasitol 2009; 164:111-117.

123. Horácio ECA, Hickson J, Murta SMF, Ruiz JC, Nahum LA. Perspectives from systems biology to improve knowledge of Leishmania drug resistance. Front Cell Infect Microbiol 2021; 11:653670.

124. Tessarollo NG, Andrade JM, Moreira DS, Murta SM. Functional analysis of iron superoxide dismutase-a in wild-type and antimony-resistant Leishmania braziliensis and Leishmania infantum lines. Parasitol Int 2015; 64:125-129.

125. Moreira DS, Ferreira RF, Murta SMF. Molecular characterization and functional analysis of pteridine reductase in wild-type and antimony-resistant Leishmania lines. Exp Parasitol 2016; 160:60-66.

126. Cioli D, Pica-Mattoccia L, Basso A, Guidi A. Schistosomiasis control: Praziquantel forever? Mol Biochem Parasitol 2014; 195:23-29.

127. Aragon AD, Imani RA, Blcakburn VR, Cupit PM, Melman SD, Goronga T, et al. Towards an understanding of the mechanism of action of praziquantel. Mol Biochem Parasitol 2009; 164:57-65.
128. Hines-Kay J, Cupit PM, Sanchez MC, Rosenberg GH, Hanelt B, Cunningham C. Transcriptional analysis of Schistosoma mansoni treated with praziquantel in vitro. Mol Biochem Parasitol 2012; 186:87-94.

129. Ferreira MS, Oliveira RN, Oliveira DN, Esteves CZ, Allegretti SM, Catharino RR. Revealing praziquantel molecular targets using mass spectrometry imaging: An expeditious approach applied to Schistosoma mansoni. Int J Parasitol 2015; 45:385-391.

130.Alonso D, Muñoz J, Gascón J, Vallo ME, Corachan M. Failure of standard treatment with praziquantel in two returned travelers with Schistosoma haematobium infection. Am J Trop Med Hyg 2006; 74:342-344.

131. Silva IM, Pereira Filho E, Thiengo R, Ribeiro PC, Conceição MJ, Panasco M, et al. Schistosomiasis haematobia: Histopathological course determined by cystoscopy in a patient in whom praziquantel treatment failed. Rev Inst Med Trop Sao Paulo 2008; 50:343-346.

132. Doenhoff MJ, Cioli D, Utzinger J. Praziquantel: Mechanisms of action, resistance and new derivatives for schistosomiasis. Curr Opin Infect Dis; 2008, 21: 659-667.

133. Melman SD, Steinauer ML, Cunningham C, Kubatko LS, Mwangi IN, Wynn NB, et al. Reduced susceptibility to praziquantel among naturally occurring Kenyan isolates of Schistosoma mansoni. PLoS Negl Trop Dis; 2009, 3(8):e504.

134. Fleming FM, Fenwick A, Tukahebwa EM, Lubanga RGN, Namwangye $\mathrm{H}$, Zaramba $\mathrm{S}$, et al. Process evaluation of schistosomiasis control in Uganda, 2003 to 2006: Perceptions, attitudes and constraints of a national programme. Parasitology; 2009, 136:1759-1769.

135. Lamberton PH, Hogan SC, Kabatereine NB, Fenwick A, Webster JP. In vitro praziquantel test capable of detecting reduced in vivo efficacy in Schistosoma mansoni human infections. Am J Trop Med Hyg; 2010, 83(6):1340-1347.

136. Vale N, Gouveia MJ, Rinaldi G, Brindley PJ, Gärtner F, Correia da Costa JM. Praziquantel for schistosomiasis: Single-drug metabolism revisited, mode of action, and resistance. Antimicrob Agents Chemother 2017; 61(5):e02582-16.

137.Zdesenko G, Mutapi F. Drug metabolism and pharmacokinetics of praziquantel: A review of variable drug exposure during schistosomiasis treatment in human hosts and experimental models. PLoS Negl Trop Dis 2020; 14(9):e0008649.

138. Buzkova H, Pechandova K, Slanar O, Perlik F. Genetic polymorphism of cytochrome P450 and methods for its determination. Prague Med Rep 2006; 107(4):383-393.

139. Wang HN, Fang ZZ, Zheng Y, Zhou K, Hu CY, Krausz KW, et al. Metabolic profiling of praziquantel enantiomers. Biochem Pharmacol 2014; 90(2):166-178.

140. Olliaro P, Delgado-Romero P, Keiser J. The little we know about the pharmacokinetics and pharmacodynamics of praziquantel (racemate and R-enantiomer). J Antimicrob Chemother 2014; 69(4):863-870.

141. Meyer T, Sekljic H, Fuchs S, Bothe H, Schollmeyer D, Miculka C. Taste: A New incentive to switch to (R)- 
praziquantel in schistosomiasis treatment. PLoS Negl Trop Dis 2009; 3(1):e357.

142. World Health Organization. Elimination of lymphatic filariasis. Wkly Epidemiol Rec 2002; 77:177-179.

143. Cobo F. Determinants of parasite drug resistance in human lymphatic filariasis. Rev Esp Quimioter 2016; 29(6):288-295.

144. Peixoto CA, Santos ACO, Ayres CFJ. Molecular evidence for apoptosis in microfilariae of Wuchereria bancrofti induced by diethylcarbamazine. Parasitol Research 2008; 103: 717-721.

145. Michael E, Malecela-Lazaro MN, Simonsen PE, Pedersen EM, Barker G, Kumar A, et al. Mathematical modelling and the control of lymphatic filariasis. Lancet Infect Dis 2004; 4: 223-234.

146. Schwab AE, Boakye DA, Kyelem D, Prichard RK. Detection of benzimidazole resistance-associated mutations in the filarial nematode Wuchereria bancrofti and evidence for selection by albendazole and ivermectin combination treatment. Am J Trop Med Hyg 2005; 73:234-238.

147. Moreno Y. Ivermectin disrupts the function of the excretory-secretory apparatus in microfilariae of Brugia malayi. Proc Natl Acad Sci USA 2010; 107:20120-20125

148. Li BW. High level expression of a glutamate-gated chloride channel gene in reproductive tissues of Brugia malayi may explain the sterilizing effect of ivermectin on filarial worms. Int. J Parasitol Drugs Drug Resist 2014; 4:71-76.

149. Sakaeda T, Nakamura T, Okumura K. Pharmacogenetics of MDR1 and its impact on the pharmacokinetics and pharmacodynamics of drugs. Pharmacogenomics 2003; 4:397-410.

150. Ardelli BF, Prichard RK. Reduced genetic variation of an Onchocerca volvulus $\mathrm{ABC}$ transporter gene following treatment with ivermectin. Trans R Soc Trop Med Hyg 2007; 101:1223-1232.

151. Bourguinat C, Ardelli BF, Pion SD, Kamgno J, Gardon J, Duke BO, et al. P-glycoprotein-like protein, as possible genetic marker for ivermectin resistance selection in Onchocerca volvulus. Mol Biochem Parasitol 2008; 158: 101-111.

152. Kudzi W, NO Dodoo A, Mills JJ. Genetic polymorphisms in mdr1, cyp3a4 and cy3a5 genes in a Ghanaian population: A plausible explanation for altered metabolism of ivermectin in humans? BMC Med Genet 2010; 11: 111.

153. Schwab AE, Churcher TS, Schwab AJ, Basáñez MG, Prichard RK. Population genetics of concurrentselection with albendazole and ivermectin or diethylcarbamazine on the possible spread of albendazole resistance in Wuchereria bancrofti. Parasitology 2006; 133:598-601.

154. Ramasamy D, Hoti SL, Sharma R, Das MK. Influence of anti-filarial chemotherapy strategies on the genetic structure of Wuchereria bancrofti populations. Mem Inst Oswaldo Cruz 2011; 106:240-247.

155.Small ST, Ramesh A, Bun K, Reimer L, Thomsen E, Baea M, et al. Population genetics of the filarial worm
Wuchereria bancrofti in a post-treatment region of Papua New Guinea: Insights into diversity and life history. PLOS Negl Trop Dis 2013; 7:e2308.

156. Reynolds MG, Oh J, Roos DS. In vitro generation of novel pyrimethamine resistance mutations in the Toxoplasma gondii dihydrofolate reductase. Antimicrob. Agents Chemother 2001; 45:1271-1277.

157. Aspinall TV, Joynson DH, Guy E, Hyde JE, Sims PF. The molecular basis of sulfonamide resistance in Toxoplasma gondii and implications for the clinical management of toxoplasmosis. J Infect Dis 2002; 185:1637-1643.

158. Meneceur P, Bouldouyre M-A, Aubert D, Villena I, Menotti J, Sauvage $\mathrm{V}$, et al. In vitro susceptibility of various genotypic strains of Toxoplasma gondii to pyrimethamine, sulfadiazine, and atovaquone. Antimicrob Agents Chemother 2008; 52:1269-1277.

159. Doliwa C, Escotte-Binet S, Aubert D, Sauvage V, Velard F, Schmid A, et al. Sulfadiazine resistance in Toxoplasma gondii: No involvement of overexpression or polymorphisms in genes of therapeutic targets and ABC transporters. Parasite 2013; 20:19.

160. Silva LA, Reis-Cunha JL, Bartholomeu DC, Vítor RWA. Genetic polymorphisms and phenotypic profiles of sulfadiazine-resistant and sensitive Toxoplasma gondii isolates obtained from newborns with congenital toxoplasmosis in Minas Gerais, Brazil. PloS ONE 2017; 12:e0170689.

161. Gajurel K, Gomez C, Dhakal R, Vogel H, Montoya J. Failure of primary atovaquone prophylaxis for prevention of toxoplasmosis in hematopoietic cell transplant recipients. Transpl Infect Dis 2016; 18:446-452.

162. McFadden DC, Tomavo S, Berry EA, Boothroyd JC. Characterization of cytochrome $\mathrm{b}$ from Toxoplasma gondii and Q(o) domain mutations as a mechanism of atovaquone-resistance. Mol Biochem Parasitol 2000; 108:1-12.

163. McFadden DC, Camps M, Boothroyd JC. Resistance as a tool in the study of old and new drug targets in Toxoplasma. Drug Resist. Updates 2001; 4:79-84.

164. Nagamune K, Moreno SN, Sibley LD. Artemisininresistant mutants of Toxoplasma gondii have altered calcium homeostasis. Antimicrob Agents Chemother 2007; 51:3816-3823.

165. Schultz TL, Hencken CP, Woodard LE, Posner GH, Yolken RH, Jones-Brando L, et al. A thiazole derivative of artemisinin moderately reduces Toxoplasma gondii cyst burden in infected mice. J Parasitol 2014; 100:516521.

166. Ma C, Tran J, Li C, Ganesan L, Wood D, Morrissette $\mathrm{N}$. Secondary mutations correct fitness defects in Toxoplasma gondii with dinitroaniline resistance mutations. Genetics 2008; 180:845-856.

167. Fairlamb AH, Horn D. Melarsoprol resistance in African trypanosomiasis. Trends Parasitol 2018; 34(6):481-492.

168. Babokhov P, Sanyaolu AO, Oyibo WA, Fagbenro-Beyioku $\mathrm{AF}$, Iriemenam NC. A current analysis of chemotherapy strategies for the treatment of human African trypanosomiasis. Path Glob Health 2013; 107:242-252. 
169. Wiedemar N, Graf FE, Zwyer M, Ndomba E, Renggli CK, Cal M, et al. Beyond immune escape: A variant surface glycoprotein causes suramin resistance in Trypanosoma brucei. Mol Microbiol 2018; 107:57-67.

170. Thomas J, Baker N, Hutchinson S, Dominicus C, Trenaman A, Glover L, et al. Insights into antitrypanosomal drug mode-of-action from cytologybased profiling. PLoS Negl Trop Dis 2018; 12:19.

171. Matovu E, Geiser F, Schneider V, Mäser P, Enyaru JC, Kaminsky, R et al. Genetic variants of the TbAT1 adenosine transporter from African trypanosomes in relapse infections following melarsoprol therapy. Mol Biochem Parasitol 2001; 117(1):73-81.

172. Matovu E, Stewart ML, Geiser F, Brun R, Mäser P, Wallace LJ, et al. Mechanisms of arsenical and diamidine uptake and resistance in Trypanosoma brucei. Eukaryot Cell 2003; 2(5):1003-1008.

173. Bernhard SC, Nerima B, Mäser P, Brun R. Melarsoproland pentamidine-resistant Trypanosoma brucei rhodesiense populations and their cross-resistance. Int J Parasitol 2007; 37:1443-1448.

174. Graf FE, Ludin P, Wenzler T, Kaiser M, Brun R, Pyana PP, et al. Aquaporin 2 mutations in Trypanosoma brucei gambiense field isolates correlate with decreased susceptibility to pentamidine and melarsoprol. PLoS Negl Trop Dis 2013; 7(10): e2475.

175. Graf FE, Baker N, Munday JC, de Koning HP, Horn D, Maser P. Chimerization at the AQP2-AQP3 locus is the genetic basis of melarsoprol-pentamidine crossresistance in clinical Trypanosoma brucei gambiense isolates. Int J Parasitol Drugs Drug Res 2015; 5:65-68.

176. Alibu VP, Richter C, Voncken F, Marti G, Shahi S, Renggli CK, et al. The role of Trypanosoma brucei MRPA in melarsoprol susceptibility. Mol Biochem Parasitol 2006; 146: 38-44.

177. Fairweather I, Brennan GP, Hanna REB, Robinson MW, Skuce PJ. Drug resistance in liver flukes. Int J Parasitol Drugs Drug Resist 2020; 12:39-59.

178. Wilkinson R, Law CJ, Hoey EM, Fairweather I, Brennan GP, Trudgett A. An amino acid substitution in Fasciola hepatica P-glycoprotein from triclabendazole-resistant and triclabendazole-susceptible populations. Mol Biochem Parasitol 2012; 186:69-72.

179. Elliott TP, Spithill TW. The T687G SNP in a P-glycoprotein gene of Fasciola hepatica is not associated with resistance to triclabendazole in two resistant Australian populations. Mol Biochem Parasitol 2014; 198:45-47.

180. Solana MV, Fernanda-Domínguez M, Scarcella S, Radio S, Smircich P, Fernández S, et al. Different SNPs in Fasciola hepatica P-glycoprotein from diverse Latin American populations are not associated with triclabendazole resistance. Mol Biochem Parasitol 2018; 224:57-60.

181. Alvarez LI, Solana HD, Mottier ML, Virkel GL, Fairweather I, Lanusse CE. Altered drug influx/efflux and enhanced metabolic activity in triclabendazoleresistant liver flukes. Parasitology 2005; 131:501-510.

182. Fernández V, Estein S, Ortiz P, Luchessi P, Solana V, Solana H. A single amino acid substitution in isozyme GST mu in triclabendazole resistant Fasciola hepatica (Sligo strain) can substantially influence the manifestation of anthelmintic resistance. Exp. Parasitol 2015; 159:274-279.

183. Leitsch D, Burgess AG, Dunn LA, Krauer KG, Tan K, Duchêne $\mathrm{M}$, et al. Pyruvate:ferredoxin oxidoreductase and thioredoxin reductase are involved in 5-nitroimidazole activation while flavin metabolism is linked to 5-nitroimidazole resistance in Giardia lamblia. J Antimicrob Chemother 2011; 66:1756-1765.

184. Uzlikova M, Nohynkova E. The effect of metronidazole on the cell cycle and DNA in metronidazole-susceptible and -resistant Giardia cell lines. Mol Biochem Parasitol 2014; 198:75-81.

185. Upcroft P, Upcroft JA. Drug targets and mechanisms of resistance in the anaerobic protozoa. Clin Microbiol Rev 2001; 14:150-164.

186. Orozco E, López C, Gómez C, Pérez DG, Marchat L, Bañuelos C, et al. Multidrug resistance in the protozoan parasite Entamoeba histolytica. Parasitol Int 2002; 51(4):353-359.

187. Muller J, Ley S, Felger I, Hemphill A, Müller N. Identification of differentially expressed genes in a Giardia lamblia WB C6 clone resistant to nitazoxanide and metronidazole. J Antimicrob Chemother 2008; 62:72-82.

188. Pal D, Banerjee S, Cui J, Schwartz A, Ghosh SK, Samuelson J. Giardia, Entamoeba, and Trichomonas enzymes activate metronidazole (nitroreductases) and inactivate metronidazole (nitroimidazole reductases). Antimicrob Agents Chemother 2009; 53(2):458-464.

189. Kazemi F, Hooshyar H, Zareikar B, Bandehpour M, Arbabi M, Talari S et al. Study on ITS1 gene of Iranian Trichomonas vaginalis by molecular methods. Iran J Parasitol 2010; 5(4):9-14.

190. Heidari S, Bandehpour M, Seyyed-Tabaei SJ, Valadkhani Z, Haghighi A, Abadi A et al. Ferredoxin genemutation in Iranian Trichomonas vaginalis isolates. Iran J Parasitol 2013; 8(3):402-407.

191. Carter ER, Nabarro LE, Hedley L, Chiodini PL. Nitroimidazole-refractory giardiasis: A growing problem requiring rational solutions. Clin Microbiol Infect 2018; 24(1):37-42.

192. Graves KJ, Ghosh AP, Schmidt N, Augostini P, Secor WE, Schwebke JR, et al. Trichomonas vaginalis virus among women with trichomoniasis and associations with demographics, clinical outcomes, and metronidazole resistance. Clin Infect Dis 2019; 69(12):2170-2176.

193. Müller J, Braga S, Heller M, Müller N. Resistance formation to nitro drugs in Giardia lamblia: No common markers identified by comparative proteomics. Int J Parasitol Drugs Drug Resist 2019; 9:112-119.

194. Lopes-Oliveira LAP, Fantinatti M, Da-Cruz AM. In vitro-induction of metronidazole-resistant Giardia duodenalis is not associated with nucleotide alterations in the genes involved in pro-drug activation. Mem Inst Oswaldo Cruz 2020; 115:e200303.

195. Loderstädt U, Frickmann H. Antimicrobial resistance of the enteric protozoon Giardia duodenalis: A narrative review. Eur J Microbiol Immunol (Bp) 2021; 11(2):2943. 